\title{
Falling share price stymies gift to university
}

Rex Dalton, San Diego

Researchers at the University of Colorado thought they had tapped a rich vein of gold last year when a Silicon Valley entrepreneur pledged \$250 million in shares for studies of cognitive disorders. But recent market falls have wiped $90 \%$ off the value of the shares, delaying some Colorado research plans and sending a warning to other institutions that accept such gifts.

The shares in BEA Systems, a businesssoftware company based in San Jose, California, were due to be donated by the company's co-founder William Coleman and his wife Claudia. The couple planned to give the university around $\$ 50$ million a year for five years to set up an endowment fund for research into areas such as developmental disabilities, Alzheimer's disease and strokes.

They gave an initial \$15 million in cash early last year to set up the Coleman Institute for Cognitive Disabilities, based at the uni-

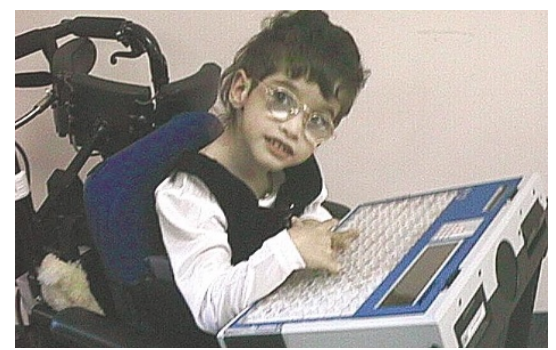

A funding pledge to back research at the Coleman Institute for Cognitive Disabilities (above) has been held up by the volatile stock market (below).

versity's Boulder campus, and to set up 15 research projects, including studies of stem cells and nerve regeneration. The rest of the year's instalment of $\$ 40$ million in stock was due to be paid last November. But the couple decided to delay the gift until 2006 when BEA's share price fell from more than $\$ 70$ to less than $\$ 20$ per share during 2001. With the

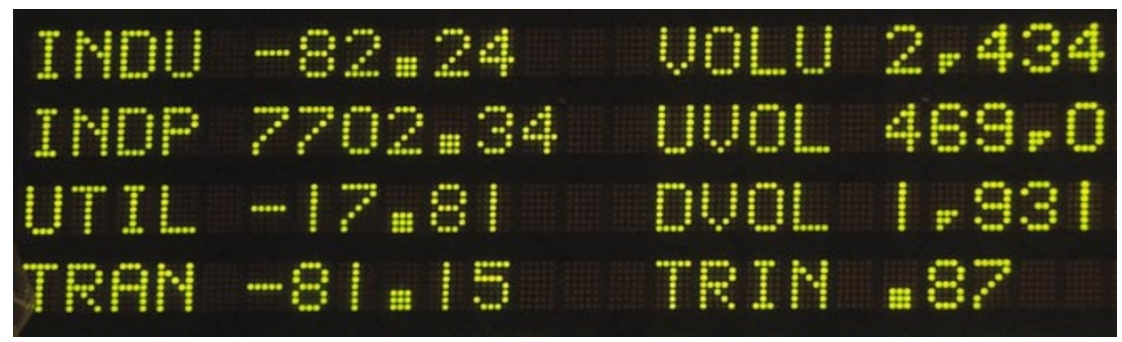

price currently at just above $\$ 5$, this autumn's \$50-million donation may also be delayed.

The Colemans have donated a further \$1.6 million to cover the income that the university would have expected to receive from its endowment, ensuring that the research projects continue. But without the security of an endowment, the university is wary of expanding too quickly and some projects have not progressed as rapidly as expected.

Shares are a common way of donating to universities, but most institutions have a policy of selling them immediately. Over the past two years, for example, the University of California, San Diego, has received a \$20-million donation from computer scientist John Moores, chairman of the board at San Diegobased software company Peregrine Systems, and his wife Rebecca. The university sold the shares immediately, and ploughed the proceeds into a new centre for cancer research and patient care, due to open in 2004. The stock, which peaked at over $\$ 60$ per share in early 2000, now stands at around 27 cents.

Patrick Mulvey, vice-president for development at the M. D. Anderson Cancer Center in Houston, Texas, says his centre was fortunate to lose only $\$ 600,000$ in pledges when Enron went bankrupt in December. The Houston-based energy company had previously given $\$ 1.6$ million to the centre. Stock market volatility is making donors wary of gifts of shares, Mulvey adds.

\section{Asteroid rating system makes an impact on the media}

\section{Jonathan Knight, San Francisco}

A new scale for assessing the risk of asteroid impacts was thrust into the limelight last week. The Palermo Technical Impact Hazard Scale is not intended for public consumption, but it sparked media interest when a two-kilometre-wide asteroid produced the scale's highest rating yet.

Since 1999, nearby asteroids have been rated on the Torino scale, in which zero represents no risk and 10 means that a globally devastating collision is almost certain. The scale was devised to communicate relative risks of asteroids to the public after media reports in 1998 that an asteroid might end civilization in 2028. Further calculations showed the asteroid to be harmless.

The Torino scale is not sensitive enough to help astronomers judge which of the dozens of nearby objects merit attention. "We wanted a way to look at a potential impact and to ask 'is it worth some big telescope time?'," says Steven Chesley, an astronomer at NASA's Jet Propulsion
Laboratory in Pasadena, California, who led the development of the new scale.

For each asteroid, the Palermo scale rates the chance of its impact relative to the frequency with which objects of a similar size collide with the Earth. A rating of zero means that an impact is no more likely than a similar but as yet unidentified object

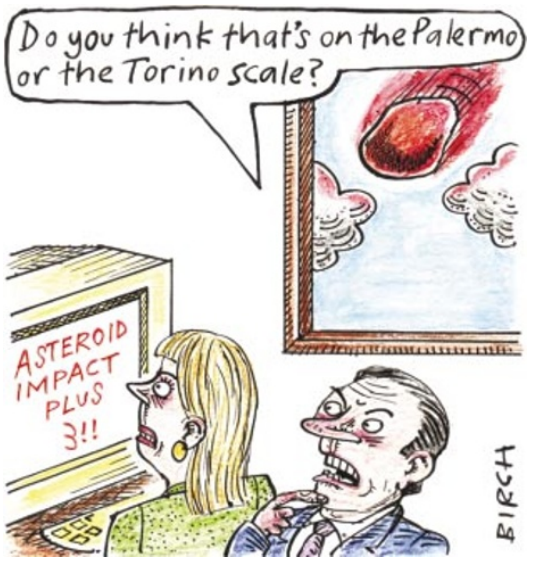

striking the Earth before the asteroid being studied is scheduled to arrive. The value is expressed as a logarithm, so -2 implies that a collision is $1 \%$ as likely as the 'background' probability, and a rating of 2 means that an impact is $\mathbf{1 0 0}$ times more likely.

Initial measurements of the trajectory of the newly spotted asteroid — dubbed 2002 NT7 - indicated that it had roughly a 1-in100,000 chance of striking the Earth in 2019. The asteroid is two kilometres across, and an object of this size is predicted to hit the Earth about every million years.

The figures gave 2002 NT7 a positive Palermo value - the first since the scale was adopted - and ensured widespread media coverage. "I was surprised to see a positive value within the first year of operation," says Chesley.

Further measurements have now reduced 2002 NT7's Palermo value to below zero and ruled out the chances of a collision in 2019, although the possibility of it striking the Earth in 2053 remains open.

http://neo.jpl.nasa.gov/risk 